\title{
The Importance of Psychological Need Satisfaction in Educational
}

\section{Re-engagement}

\section{Laura J. Nicholson ${ }^{\mathrm{a}}$ and David W. Putwain ${ }^{\mathrm{b}}$}

${ }^{a}$ Faculty of Education, Edge Hill University, Ormskirk, Lancashire, UK

${ }^{b}$ School of Education, Liverpool John Moores University, Liverpool, UK

Corresponding author: Laura J. Nicholson, Faculty of Education, Edge Hill University, Ormskirk, L39 4QP, UK. Email: laura.nicholson@edgehill.ac.uk. Tel: 01695 657277, Fax: 01695579997

Dr Laura J. Nicholson is a Research Associate in the Faculty of Education at Edge Hill University. Her research interests focus on student engagement (including the factors that influence and are influenced by it) and attitudes towards literacy development.

David W. Putwain is a Professor of Education in the School of Education at Liverpool John Moores University. His interests focus on the psychological factors that influence and, in turn, are influenced by learning and achievement. These include motivation, engagement, emotions (particularly fear of failure) and the psychosocial classroom environment.

Acknowledgements: The authors would like to thank Jenna Edwards for her help with data collection and transcribing. 
Students attending alternative provision (AP) schools have typically disengaged with their education. They present with multiple problems and complex support needs which makes their re-engagement back into education challenging. This study examined educational reengagement using the self-system model of motivational processes. Teacher (or other school staff) practices that facilitated and inhibited the students' psychological needs for autonomy, relatedness and competence were identified. Semi-structured interviews were conducted with 35 students (aged 14-16 years) attending an AP school in England and data were triangulated using staff interviews and lesson observations. Interpretive phenomenological analysis was used to code the data. More staff practices were categorised as facilitating one of the three needs, and more students mentioned these positive behaviours, than the need-inhibiting practices. This fostered trusting, caring and respectful student-staff relationships, which ultimately led to educational re-engagement. It would be beneficial if such findings were incorporated into government statutory guidelines for AP establishments in order to increase awareness amongst those on the frontline. Moreover, findings support the current UK government policy to increase the number of AP schools, as they have the scope to focus on the supportive staff practices.

Keywords: student re-engagement, alternative education, self-system model, psychological needs, student-teacher relationships

\section{Introduction}

This study examined the re-engagement of initially disengaged students attending an alternative provision (AP) secondary school. AP is education arranged for students who have left mainstream education permanently or for a fixed period. There are multiple and interrelated reasons why students leave mainstream school including exclusion, poverty, alcohol and substance abuse, violent behaviour, bereavement, mental health issues, physical disability, illness, teenage pregnancy and bullying (Cook 2005; DfE 2013b). Thus, AP 
students have unique educational histories and often present with complex support needs, including behavioural, emotional, social and learning difficulties (Pirrie, Macleod, Cullen, and McCluskey 2011). In the long term, they are at increased risk of a range of negative outcomes, such as poor mental and physical health, homelessness and involvement in crime (Pirrie et al. 2011). Their re-engagement back into mainstream education presents a significant challenge as conventional routes may be inappropriate (Cook 2005). In the UK, alternative education is arranged by local authorities or schools, is provided away from the site of the school, and pupils attend as part of their regular timetable (Ofsted 2016). A common focus is to re-engage pupils in their education, as well as to prevent exclusions and improve behaviour (DfE 2013a; Ofsted 2016).

The present study extends previous research, that has identified factors influencing reengagement, with the use of a theoretical framework in which teacher, and other school staff, practices were examined. The aim was to draw on the self-system model of motivational processes (Connell and Wellborn 1991) to categorise staff behaviours into facilitators and inhibitors of students' psychological needs for autonomy, relatedness and competence. In keeping with this model, the primary focus was to investigate the students' experiences of the fulfilment of their needs, and the use of qualitative methods, specifically semi-structured interviews, allowed us to understand their phenomenology. We triangulated the student data using staff interviews and lesson observations in order to increase the trustworthiness and robustness of results.

The current paper begins with a literature review on the self-system model, teacher practices, alternative education, including current policy in the UK, and an outline of the aim. This is followed by full details of the method, findings, in which themes are categorised according to whether they facilitated or inhibited the three psychological needs, and a discussion of results, including a consideration of limitations and implications. 


\section{Literature review}

\section{The self-system model of motivational processes}

The self-system model of motivational processes (Connell and Wellborn 1991) is based on the premise of self-determination theory (SDT) that individuals have three fundamental psychological needs: the need for autonomy, relatedness and competence (Deci, Vallerand, Pelletier, and Ryan 1991; Ryan and Deci 2000). Broadly speaking, autonomy is the need to express one's authentic self and to experience connectedness between one's actions and personal values, relatedness refers to the need to feel securely connected to others or to belong to a social group, and competence is the need to feel capable of producing desired outcomes and avoiding negative outcomes (Connell and Wellborn 1991; Furrer, Skinner, and Pitzer 2014). From an educational perspective, SDT suggests that students will be engaged in their learning when their learning environment satisfies these three needs. When the need for autonomy is met, students become self-regulated learners and internalise the value of school (Connell and Wellborn 1991). When the need for relatedness is satisfied, students feel connected to teachers and safe at school (Furrer et al. 2014). Finally, when the need for competence is fulfilled, students perceive themselves as academically competent, know how to do well in school and believe in their own capabilities (Connell and Wellborn 1991; Furrer et al. 2014).

The self-system model (Connell and Wellborn 1991) proposes that satisfaction of the three needs in the context of the classroom is determined by factors that either support or inhibit them, i.e., autonomy support versus coercion, relatedness involvement versus rejection, and competence structure versus chaos. The extent to which the needs are met influences student engagement, which consists of affective (e.g., interest in and enjoyment of school), cognitive (e.g., investing effort into learning) and behavioural (e.g., high attendance) elements (Fredricks, Blumenfeld, and Paris 2004), and in turn, is the most proximal predictor 
of academic achievement. The full model is illustrated in Figure 1. Previous research has established the proposed links between contextual factors, student engagement and academic achievement, including the mediating role of student engagement (Fredricks et al. 2004; Furrer and Skinner 2003; Reschly and Christenson 2012; Van Ryzin, Gravely, and Roseth 2009; Zimmer-Gembeck, Chipuer, Hanisch, Creed, and McGregor 2006). Classroom factors that specifically support or inhibit satisfaction of the three psychological needs have been found to predict student engagement (Park, Holloway, Arendtsz, Bempechat, and Li 2012; Roeser, Eccles, and Sameroff 1998) and self-perceptions of need satisfaction have been found to mediate these relationships (Dupont, Galand, Nils, and Hospel 2014).

Insert Figure 1 here

\section{Teacher practices}

The present research is concerned with how teachers can support or inhibit student engagement. The quality of the student-teacher relationship is crucial to student engagement (Decker, Dona, and Christenson 2007; Furrer and Skinner 2003; Roorda, Koomen, Spilt, and Oort 2011), and it is useful to interpret the supporting and inhibiting contextual factors identified in the self-system model within the realm of this relationship (Furrer et al. 2014; Skinner and Belmont 1993; Zimmer-Gembeck et al. 2006). Ryan and Deci (2009) emphasised the critical role that teachers play in creating a classroom climate that either supports or inhibits the needs of autonomy, relatedness and competence, and Pianta, Hamre, and Allen (2012) argued that classroom settings should support these needs specifically via the student-teacher relationship, as this is the primary mechanism by which student engagement is fostered. The self-system model provides a useful theoretical framework whereby teacher behaviours can be organised into higher order categories to explain the mechanisms by which they influence student need satisfaction and engagement (Skinner and Belmont 1993). Moreover, the focus on contextual factors that are under the control of 
schools and teachers allows specific recommendations to be made to educators on how to improve student motivation, engagement, and subsequent academic performance (Appleton et al. 2008).

According to the self-system model, students who are labelled 'at-risk' based on their previous academic performance, suspension history and attendance record, have a greater need for autonomy support, relatedness involvement and competence structure (Connell and Wellborn 1991). Positive student-teacher relationships may promote resiliency and protect atrisk students from adverse school outcomes, such as disengagement from school (Decker et al. 2007; Dotterer and Lowe 2011). In particular, the relatedness element of the relationship is crucial to the engagement of at-risk students (e.g., Decker et al. 2007; Dotterer and Lowe 2011; Knesting and Waldron 2006; Muller 2001). Structure in the classroom, high expectations and demonstrating confidence in students' abilities have also been found to be associated with engagement in academically at-risk students (Dotterer and Lowe 2011; Knesting and Waldron 2006). Positive support and feedback from important others (e.g., teachers) promote self-efficacy and a sense of competence over the task, which improves attainment and partly mediates the effects of demographic variables such as gender and ethnicity on performance (Lent, Brown, and Hackett 1994). Roorda et al. (2011) identified a gap in the literature and called for future research to investigate the impact of student-teacher relationships on academic functioning in students with behavioural problems.

\section{Alternative education}

Previous research on alternative education has identified a number of factors that have facilitated or inhibited student re-engagement, which can be categorised according to the needs for autonomy, relatedness and competence. To facilitate autonomy, teachers/staff members need to show students respect, provide flexible learning opportunities, design relevant and personally applicable lessons, provide opportunities to debate choices and 
values, and avoid attempts at control (D'Angelo and Zemanick 2009; Frankham, EdwardsKerr, Humphrey, and Roberts 2007; Hallam, Rogers, Rhamie, Shaw et al. 2007; Schussler 2009). Regarding relatedness, teacher caring and support is a critical facilitator for reengaging students. When school staff build a relationship of trust where they know students personally, show that they care and want to help students, express understanding in response to disruptive behaviour, and help students to believe that they belong in the classroom and school community, students are more likely to re-engage with them and ultimately, with their education (Cook 2005; D’Angelo and Zemanick 2009; Frankham et al. 2007; Jones 2011; Pirrie et al. 2011; Schussler 2009; Tobin and Sprague 2000). To support the need for competency, teachers/staff members should create a highly structured classroom in which expectations for schoolwork and behaviour are taught and reinforced, provide an optimal level of challenge, offer frequent positive feedback, convey high expectations, and demonstrate the belief that students are capable of academic success (D'Angelo and Zemanick 2009; Frankham et al. 2007; Schussler 2009; Tobin and Sprague 2000; White, Martin, and Jeffes 2010). Support for all three needs would result in an ideal classroom context. Schussler (2009) reported high levels of re-engagement when the teacher knew the students as individuals well enough to provide instruction that challenged them, tapped into their interests and was relevant to their lives, and when students felt that their teacher supported them and cared about their grades.

\section{Policy in the UK}

In the UK, it is policy to place a child or young person into full-time AP no later than the sixth day of exclusion or voluntary removal from mainstream school (DfE 2013a). AP was traditionally provided by pupil referral units (PRUs), which are establishments set up and maintained by the local authority, to provide short-term education for children and young people unable to attend mainstream school, until they are placed in permanent education. 
PRUs are currently being encouraged to convert to AP academies (DfE 2015b). Although academies were in existence beforehand (traditional academies), the Academies Act 2010 allowed all publicly funded schools to apply to become academies (academy converters). Traditional academies are typically underperforming state schools set up by a sponsor, such as a university or college, while academy converters tend to be existing high performing schools, which opt out of local authority control to gain independence. Free schools were also given approval in 2010, which differ from academies in that they are usually brand new schools that can be set up by a range of groups and organisations including teachers, parents, charities and trusts. Both types of academies and free schools can offer AP, and in opposition to state (mainstream) schools, are free from local authority control, therefore having more autonomy over their curriculum, budget and staff (DfE 2015a). UK government statutory guidance requires AP establishments to aim to (i) achieve good academic attainment on par with mainstream schools, (ii) meet the personal, social and academic needs of pupils, (iii) improve student motivation, self-confidence, attendance and engagement with education, and (iv) identify the next steps following the placement (e.g., further education, employment; DfE 2013a).

A recent survey, commissioned by the DfE, compared schools' use of AP over the course of three years (Ofsted 2016). Although several weaknesses remained (e.g., some alternative providers were not registered with an official body which carries risks; there were some serious safeguarding concerns and the majority of AP staff had not received any child protection training; sometimes only a narrow range of subjects could be studied; some students could only take low level English and mathematics qualifications), many aspects had improved (e.g., almost all AP establishments were of at least a reasonable standard; schools were ensuring that their chosen AP was safe and suitable for their pupils; more schools tracked the impact of AP on pupil's personal development and well-being). Government 
policy currently encourages primary and secondary schools to become academies and is working at increasing the number of free schools in the UK (DfE 2015a).

\section{The present study}

The present study represents the first time that the self-system model has formally been applied to the re-engagement of disengaged students attending an AP (free) school. The aim was to identify teacher (or other school staff) behaviours that facilitated and inhibited the psychological needs for autonomy, relatedness and competence. It is well-established in the literature that student reports are the best source of information on engagement and disaffection (Appleton, Christenson, Kim, and Reschly 2006; Martin 2007; Reschly and Christenson 2012; Schussler 2009; Skinner, Kindermann, and Furrer 2009). According to the self-system model, it is the students' experience of autonomy support/coercion, involvement/rejection and structure/chaos that influences the development of their selfsystem (Conner and Wellborn 1991). It follows that studies of the contextual aspect of the model should focus on student perceptions and perspectives (Conner and Wellborn 1991; Reschly and Christenson 2012). Most psychological research relies on a quantitative methodology (e.g., Madill and Gough 2008), however, qualitative methods are warranted to understand the phenomenology and lived experience of psychological constructs such as engagement and the needs for autonomy, relatedness and competence. Further, they can illustrate how students construct the meaning and purpose of education in a highly complex and sometimes contradictory school environment (Fredricks et al. 2004), and therefore go some way towards taking account of students' habitus (Bourdieu and Passeron 1977) and horizons for action (Hodkinson and Sparkes 1997).

Due to this literature base, semi-structured interviews were conducted with the students of the AP school to elicit information about their psychological needs and engagement. Self-reports can be vulnerable to biases such as social desirability, therefore, in 
order to increase the trustworthiness and robustness of the results, additional information was obtained from multiple sources and using multiple methodologies (Dotterer and Lowe 2011; Greene 2015; Martin 2007; Roeser et al. 1998; Sinatra, Heddy, and Lombardi 2015; ZimmerGembeck et al. 2006). Specifically, staff interviews and lesson observations also informed the research and were used to triangulate the student interview data. In some cases, observation of students provides a more direct route to behaviour and a deeper insight into their experiences (Cotton, Stokes, and Cotton 2010).

\section{Method}

\section{Participants and their setting}

Staff and students at an English AP free secondary school took part in the study. The school was selected as it was the only new AP free school in the locality. Although the school is described in singular terms, educational provision was spread across three sites (used for a various other purposes), due to a rapid expansion of the school during its first year of opening. Two of the sites were located in suburban areas and one urban, and all comprised at least two classrooms, office space, student recreational spaces and other facilities (e.g., sports facilities). Almost all students had either been excluded from, or refused to attend, their mainstream secondary school (or other AP provision). This was due to a range of problems including poor records of attendance at their previous school (typically 10-20\%), fighting with peers, bullying, pregnancy and anxiety. Family backgrounds were described by staff as 'challenging' and included issues such as homelessness, parental substance addiction, abuse, gang culture and violence. At the AP school, students followed a reduced academic curriculum, in which they worked towards the statutory General Certificate of Secondary Education (GCSE) program of study ${ }^{1}$ in English, mathematics and science, took compulsory

\footnotetext{
${ }^{1}$ In England, the GCSE program of study is taken over the final two years of secondary education and leads to school exit examinations.
} 
lessons in physical education (PE), and were able to choose their subject of study from several academic (GCSE Art or Media Studies) or vocational (e.g., health and beauty, construction) subjects, for one day per week. Class sizes were small and there were typically two-three members of staff present in each lesson, consisting of the class teacher and either a lesson support assistant, student teacher and/or a behaviour and welfare assistant (to ensure a safe environment). The median staff-to-student ratio observed was 2:5.

Sixty students (42 male 18 female, aged 14-16 years) were enrolled at the school at the time of data collection. There were 37 members of staff ( 23 male 14 female), including teaching and lesson support staff, behaviour and welfare staff, school managers, and therapeutic engagement staff (supervised by a clinical psychologist) ${ }^{2}$. Thirty-five students (23 male 12 female) and all staff members took part in the interviews. Data were not systematically collected on ethnicity, disability or learning difficulties, as it was not pertinent to the research aim, however, some students mentioned these issues during their interview. In addition, it is noted that none of the students interviewed displayed visible physical disabilities, and all were able to verbally participate in their interview.

\section{Procedure}

The AP school opened in September 2012 and data were collected during a three-week fieldwork visit in the middle of its second academic year. The two authors and a research assistant conducted the interviews and lesson observations, all of whom had received appropriate training and experience in these methods. Written consent was obtained from all participants, and they were informed of their right to withdraw their data and that any data supplied would be stored and reported confidentially and anonymously.

\footnotetext{
${ }^{2}$ All staff members were heavily involved with students and many staff had multiple roles within the school. Therefore, the 'student-teacher relationship', as it is termed in the majority of past research (typically on students attending mainstream school), is referred to as the 'student-staff relationship' here. Also, unless the discussion is exclusive to teachers, the term 'staff' is used to encompass the variety of roles.
} 


\section{Interviews with students}

One-to-one semi-structured interviews were conducted with students to elicit information about their needs for autonomy (e.g., 'How much choice do you get in lessons?'), relatedness (e.g., 'How do you get on with the staff?') and competence (e.g., 'How difficult is your schoolwork?'), their affective (e.g., 'How do you feel about this school?'), cognitive (e.g., 'How important is getting an education to you?') and behavioural (e.g., 'What is your attendance like at this school?') engagement, and their academic progress at the school. We followed the approach advocated in Brinkmann and Kvale (2014) of using a build-up phase to establish rapport with the student, followed by the main schedule of questions, and finally a cool-down phase to conclude the interview. All interviews took place either in an unoccupied classroom or in a quiet area of the site cafeteria during the school day, and only the interviewer and student were present. Interviews were audio-recorded, lasted between 5 and 36 minutes and were transcribed verbatim.

\section{Interviews with staff}

The semi-structured interview schedule for staff included questions about the general approach to teaching and how the staff attempted to create an environment that would help to promote a re-engagement with learning. In particular, staff were asked questions designed to provide information on how students' needs for autonomy (e.g., 'Do you try to create an environment that supports student autonomy? How?'), relatedness (e.g., 'How do you create an environment which helps students to feel part of and identify with the school?') and competence (e.g., 'How are you able to support progress in a class of students with such diverse levels of ability?') were supported (or inhibited). Again, the procedure suggested by Brinkmann and Kvale (2014) was followed. All one-to-one interviews took place in a vacant classroom or common room during or at the end of the school day, and were audio-recorded, transcribed verbatim and lasted between 12 and 54 minutes. 


\section{Lesson observations}

Semi-structured observations were conducted in which teacher behaviours were recorded using an adapted version of the schedule developed by Roehrig and Christesen (2010; see Putwain, Nicholson, and Edwards 2015). Specifically, field notes were recorded on teacher practices that have been found to promote or inhibit the needs of autonomy, relatedness and competence, for instance, encouraging behavioural self-regulation, fostering a sense of community, and expression of high expectations. A group discussion between all three observers took place prior to the lesson observations regarding the teacher practices to be recorded to ensure complete understanding, and each observer possessed a document containing examples of each teacher practice. We aimed to observe at least two lessons per day, and the selection of lessons was opportunistic. A total of 29 one-hour lessons were observed by one member of the research team and this included lessons in English, mathematics, science, PE, art and media studies.

\section{Data analysis}

Data were coded along the principles of interpretive phenomenological analysis (IPA; Smith and Osborn 2003; Smith, Flowers, and Larkin 2009). The goal of this method is to understand the meaning of lived experiences from the perspective of the individual (Pietkiewicz and Smith 2014) and it is applicable to observational as well as interview data (Smith et al. 2009). The analysis was inductive, a priori concepts and themes were not imposed on the data, and each transcript was analysed separately to maintain its idiographic commitment (Pietkiewicz and Smith 2014; Smith et al. 2009). Consistent with the principles of IPA, data from the student interviews, staff interviews and lesson observations were analysed separately in order to preserve any differences that might have emerged between them. The student interviews were analysed by the first author and provided the primary source of data for the current paper. Following initial case familiarisation, emergent themes were identified for each 
transcript (i.e., student) and subsequently clustered across all transcripts (students) on the basis of similarity. The student data were triangulated using the data derived from the staff interviews and lesson observations, which were coded by the second author. On completion, the cluster themes were interrogated against all data to identify and resolve disconfirmatory cases by both authors. They were then classified as facilitating or inhibiting one of the three psychological needs.

\section{Trustworthiness of data}

In order to increase the trustworthiness of the data and findings, several strategies proposed by Lincoln and Guba (1985) were followed including prolonged engagement in the research setting, persistent observation, peer debriefing, negative case analysis, thick description and keeping an audit trail. Further, detailed member checks were conducted. Initially, a six-panel committee comprising school managers and teaching staff reviewed the complete analyses of student and staff interviews and lesson observations. Feedback on this document was then provided at a subsequent meeting with all teaching and lesson support staff, in which other staff were invited to comment. No substantial interpretive differences arose.

\section{Findings}

The cluster themes were categorised according to whether they facilitated or inhibited the needs for autonomy (support versus coercion), relatedness (involvement versus rejection) and competence (structure versus chaos; see Figure 1).

\section{Autonomy Support}

The themes of respect, choice, flexibility, non-confrontation, personal relevance, and value of education were identified as indicators of autonomy support.

Respect

Students, almost unanimously, believed that teachers and other school staff treated them and spoke to them with respect and 'like an adult'. This represented a major difference to the way 
that they were treated at their previous school(s). They reciprocated by showing respect back. Students were also allowed to address teachers by their first name (rather than 'Miss'/'Sir' which is typical in mainstream secondary schools), which students perceived to be a reflection of mutual respect between staff and students.

\section{Choice}

Students were given choice over many aspects of their school-life. The following extract shows how choice was promoted by staff at the AP school.

...we do talk a lot about the choices that they are making. I will try to use that sort of language with the students a lot. Choice is a really powerful word with these sorts of kids because they have never had the choice before. (Male staff member)

Students enjoyed being able to choose the focus of their work, such as what they painted in art lessons. One student described how, in her English lesson, they could choose the topic of a piece of creative writing. As shown below, she explained that this made the task more interesting and enjoyable which improved the quality of her work.

I like boxing, the boxing show I done mine on, based on that, cos I knew about it and I enjoyed about it, like, I enjoyed writing about it. I done dead good in the end. (Female student)

\section{Flexibility}

Students explained that teachers were flexible and would change their lesson plan if the students did not want to complete the planned work. One teacher described an incidence where they judged that their students were unlikely to make progress in a traditional lesson and consequently took students offsite for an educational visit. Further, during a lesson observation, students refused to participate in a scheduled test, and so the teacher negotiated with them that they would take the test the following day. Students described how lessons were relaxed and informal, for instance, they were allowed to talk and 'chill out' while they worked, finish incomplete work during the next lesson, and take five minutes out of the 
classroom if they felt stressed or agitated (even while taking a test). This helped students to feel comfortable, and that the school 'understood' them and the optimal environment they needed to learn and engage.

\section{Non-confrontation}

Students reported that (most) staff rarely shouted at them, which contrasted with their previous school experiences. The following extract illustrates the student belief that shouting at students with behavioural and/or social problems would only cause more anger.

In my old school they used to get right in your face and scream in front of everyone so I would scream at them back but the teachers up here they take you outside or take you on a walk to calm you down and then they talk to you. (Male student)

When a student became disruptive at the AP school, staff remained non-confrontational and allowed them to leave the classroom with a staff member while they calmed down, reflected on their behaviour and attempted to identify the triggers that may have led to the disruption. Students appreciated this approach and explained that a crucial aspect was that staff understood that troublesome behaviour was often a manifest of the students' personal problems. Staff also reported that the approach showed positive results over time.

\section{Personal relevance}

Students participated and enjoyed lessons more when they included an activity with which they could relate to personally. They explained that if the topic was relevant, they were more willing to learn and 'push' themselves to achieve. The lesson observations revealed many ways in which teachers attempted to increase the relevance to students. For example, in science lessons, the teacher used sweets to teach about compounds, in drama lessons, the teacher changed the play they were studying, and as shown below, the coursework topic in English lessons was gun crime which had both age and local relevance.

In English they are doing like gun crime and there's a lot of like articles about [name of city omitted]. So obviously a lot of them say 'Oh my God that's right by mine' [where I live] or 
whatever and that sort of instantly gets their attention rather than doing something that means nothing to them. (Female staff member)

\section{Value of education}

Students explained that staff had spent time explaining that they needed to get a job and that education was the way to secure one. It was clear that they had internalised this belief. Students described how the AP school had changed their attitude towards education and they felt motivated to 'do well' academically. Specifically, one student appreciated the purpose of recording his achievements on his curriculum vitae, as he could see the link between his work efforts and the ultimate goal of securing a job.

\section{Autonomy Coercion}

Attempts to control, threats and punishments, and communication problems were classed as indicators of autonomy coercion.

\section{Attempts to control}

Despite the evidence presented earlier, students reported that certain staff members did shout at students. During a lesson observation, the teacher became frustrated by the lack of students' cooperation. Students reacted to the teacher's frustration by becoming confrontational, resulting in a rapid escalation of disruptive behaviour. Other attempts at controlling students included the expectation that they should stay behind at the end of the school day to participate in an extracurricular scheme. The following quotation highlights the student view that they were being pressured to attend the scheme, rather than it being a freely chosen activity.

She makes us go to [name of building in which scheme takes place]. No-one wants to and she threatens to rip our contracts up [with the school] and everything. She says if we don't do certain things she is going to rip our contracts up. (Male student)

\section{Threats and punishments}


In general, the school promoted a non-punitive approach to managing student behaviour. Students appreciated this, for instance, they explained that they 'couldn't deal' with detentions at mainstream school and that they had caused arguments with teachers. Despite this, some teachers used threats and punishments as a behavioural control strategy. For example, students explained that they would not be allowed a break if they had been disruptive, one teacher was observed telling students that they would fail a GCSE as they were not engaging in class, and one student said she was not allowed to attend a school excursion because of poor attendance.

\section{Communication problems}

Some students believed that staff had not explained the reasons for decisions that affected them and their learning. For instance, one of the GCSE subjects was removed from the timetable with no apparent explanation, resulting in students feeling that they had 'wasted their time' completing coursework. In response to student-student conflict, a minority of students felt that staff had not listened to their opinions, given them options, or justified their decisions to them. Other students, however, believed that their viewpoints had been considered and acted upon.

\section{Relatedness Involvement}

For relatedness involvement, the themes were knowing students, care, understanding and support, and peer relationships.

\section{Knowing students}

As shown below, students reported that staff made an effort to get to know them on a personal level, and spent time with them before and after school and during breaks. ...in a normal, in a mainstream, school, like, the teachers have the staffroom and that, don't they? In here they share, like, they have their break with you, they have their dinner with you, they have their third break with you, like, they don't get any time on their own or anything and they just want to be with you and they want to help you. (Female student) 
Staff further explained that they would ask students about their home circumstances and interests. Many incidences of informal talk between staff and students were observed, in which staff would prompt discussions and ask questions such as, 'How are you?' and 'What are you doing on Friday?'. This enabled staff to get to know students more intimately than would be typical in a mainstream school and, as one teacher commented, '...it allows you into their lives'. Students explained that this approach allowed staff to (i) understand their problems, resulting in them being more understanding and willing to help, (ii) understand their goals, enabling them to more effectively guide them, and (iii) know when they were acting out of character, which helped them to respond appropriately. Students explained that they also knew staff on a personal level and viewed them more as friends.

\section{Care, understanding and support}

The student belief that staff cared for them was in marked contrast to the universal belief that teachers at their previous school(s) did not care. As demonstrated below, many students felt able to talk to staff as they would take the time to listen, understand and try to find a solution. Staff were seen to put students' needs first and were viewed as approachable and understanding. This approach was described as a 'good support system'.

Here they wanna help you. So if you are having a problem in your class you come down here to, like, Paul [pseudonym] or Rob [pseudonym] and they just, Paul's like the best person ever to me in this school, like, I just know I can tell him anything and he will just help me. I used to like keep things to myself but Paul just always gets it out of me, he's like the best teacher ever. (Female student)

The following two extracts illustrate that staff at the AP school understood that the cause(s) of disruptive behaviour lay in the students' background, which may have stemmed from childhood (e.g., attachment issues), chaotic or unpredictable current home lives, and/or negative prior educational histories. 
...when I am, like, not at my best one day I might like do teacher's head in and that there will be a reason behind it, like, I might have had a bad weekend or something, just want to like you know get stuff off my chest and that but, like, teachers they know that about you, like, they know why you're playing up and like not to just shout at you. (Female student) When they [AP students] confide in you, you find out stuff about what they have been through. It totally changes the way you look at everything, the way you teach them and the way you react to things they do. (Male staff member)

Another student explained that staff understood that she had anxiety problems, whereas her mainstream teachers had accused her of not listening in class. Students also believed that staff cared about their future, and went to lengths to support them in their career choices, for instance, by organising employment opportunities.

\section{Peer relationships}

Staff encouraged nurturing student-student relationships. For instance, teachers would explain the importance of listening to and respecting the opinions of other class members. Students explained that they worked together 'as a big team' and helped each other out with their work, which was confirmed in the lesson observations. Receiving help from peers was something the AP students had not experienced in their previous school(s). In lessons, the language that staff used promoted a sense of togetherness, for instance, they would refer to 'we' rather than 'you'. Students also explained how staff ensured that all of the students learned the material and were involved in class discussions. Students felt included and not 'left out', and this increased confidence in speaking out in the classroom. Positive relationships between students fostered a sense of belonging to the school, which some students referred to as a 'big family'.

\section{Relatedness Rejection}

The themes of demonstrating irritation and unfair treatment represented relatedness rejection.

\section{Demonstrating irritation}


Some students, although reporting that they had good relationships with the majority of staff, complained that other staff members were 'narky', temperamental or less willing to help with students' problems. Specifically, several students at one site disliked the site lead, and one student explained how the behaviour and welfare officer could be confrontational and had behaved provokingly towards a student in the past.

\section{Unfair treatment}

A minority of students described feeling frustrated because they felt that students in a different class received more privileges, such as going on more school excursions. Other students explained that they had been treated unfairly in response to student-student conflict; they believed that staff favoured either long-standing students, new students and/or students who involved them in 'petty' arguments. One student described how a classmate had insulted her, which led to her skipping school. She was punished for this by not being allowed to attend a school excursion, when the perpetrator of the incident was allowed to attend, which she felt was unfair.

\section{Competence Structure}

Clarity in teaching and expectations, optimal challenge level, classwork support, and confidence in students were classified as indicators of competence structure.

\section{Clarity in teaching and expectations}

A teacher explained the importance of structure for the AP school students in the following quotation.

They [AP school students] need very, very, structured lessons where they are told 'you will do this' and 'you do that' so I find engagement takes a lot more planning... if you get your lesson plan wrong it's a long way back. I mean once they've gone, to rein them back in. (Female staff member)

Students described how teachers spent time explaining the content of the lesson thoroughly and making sure that all of the students understood the material. Teachers were observed 
using lots of explanation to help students understand the purpose of lessons and tasks. Expectations about behaviour were also frequently communicated and teachers managed disruptive behaviour by maintaining a constant vigilance over the class activity, which was facilitated by small class sizes.

\section{Optimal challenge level}

Students reported that, on their arrival at the school, staff identified the level at which they were working and regularly monitored their progress to ensure an optimal level of challenge. This approach seemed successful for many students as the complexity level of the work was described as 'just right'. Students explained that staff would tailor the difficulty of the work to individual students by providing further support on a one-to-one basis, making the task easier, or on the other hand, by offering more challenging work or homework. Some students found the work difficult but viewed this as necessary for improvement. It was observed that students were quick to communicate when they found something too challenging or boring, which alerted staff to provide some individual support.

\section{Classwork support}

Class size was unanimously perceived by students to be crucial to their ability to engage in their learning. The low staff-student ratio ensured that staff were readily available to support students as soon as they became stuck or started to get distracted, which students said led to better concentration and learning. Lesson observations revealed that if students did not receive immediate support, they would become disruptive or, if particularly frustrated, refuse to work or leave the classroom. Students said that this was typical of their previous school experiences.

\section{Confidence in students}

Students reported that their previous teachers had never encouraged or praised them and consequently they did not make the effort to learn. In contrast, students felt that staff at the 
AP school were encouraging and 'wanted' them to achieve. As the following quotation demonstrates, the student perception that staff believed in them actively promoted their own self-belief that they would achieve. Ultimately, students became determined to be successful. ...most of the teachers have said when I leave this school I will be so successful... all the staff, teachers, learning mentors, they are so supportive and they just wanna, they just wanna see you do the best that you can and they just wanna see you, erm, just doing your best really and going on to achieve something big. (Male student)

Teachers were observed frequently praising students for on-task behaviours, focused attention and completed work, as well as for making an effort rather than giving a correct answer.

\section{Competence Chaos}

For competence chaos, the themes were competition and incorrect challenge level.

\section{Competition}

A minority of instances were detected in which competition or comparison between peers were promoted. One student reported that student attendance levels were put on display during a lesson. She did not appreciate her classmates being able to see her attendance record, especially as they made unsupportive comments such as, 'Oh you only got $60 \%$ '. A class was observed being informed that they were 'ahead' of another class, and also, at the students' request, test scores were read out to the whole class. One teacher told how they would sometimes attempt to foster friendly competition between students as a motivation tactic but that its success was variable. Students reported that they did not feel in competition with each other academically, but that they enjoyed 'friendly' competition, which they viewed as motivating.

Incorrect challenge level 
Some students reported that the work was too difficult, which led to frustration and anger, and ultimately a state of helplessness. As shown below, this again highlights the importance of staff being readily available to help.

If I don't get help I will give up but, like, teachers come and help me, like, I don't give up I just feel like I can't do it and if I do it, it will be wrong anyway. (Female student) Conversely, another student complained that staff did not 'push' them or set them goals, and many students were unaware of whether or not they were meeting their academic targets. Some students specifically struggled with the pace of delivery, while others had difficulty with the length of time they spent completing the same piece of work.

\section{Outcomes of teaching practices}

The themes derived from the student interviews represent staff practices that students said helped to define the student-staff relationship. Most of the behaviours were categorised as facilitating, rather than inhibiting, one of the three needs, and more students mentioned these positive actions, than the negative, need-inhibiting practices. Consequently, students reported good relationships with staff. This was a striking and distinctive quality of the AP school. The following quotation illustrates the impact that students felt that the staff had on their experience.

...the staff, like, I'm really proud of myself as well, like, I just couldn't do it if they [AP school staff] weren't here to be honest, yeah it's such a great school. (Male student)

Students felt as if they could learn and make progress in the context of these positive studentstaff relationships. Specifically, they said they were more prepared to engage, try, persist, and ask for help in the classroom, as well as being less likely to get into trouble, compared to when they were at their previous school(s). They also reported increases in their attendance, enjoyment of school, value of education, psychological well-being and academic achievement during their time at the AP school, and they attributed this to the positive student-staff relationships. Data from the staff interviews corroborated these positive 
outcomes, and staff emphasised that there had been a major improvement in the school attendance records and behavioural conduct of the majority of students. Therefore, students appeared affectively, cognitively and behaviourally engaged in their studies.

\section{Discussion}

The self-system model of motivational practices was applied to the re-engagement of disengaged students attending an AP school. Themes representing teacher behaviours in the classroom were identified and categorised according to whether they facilitated or inhibited the psychological needs for autonomy, relatedness and competence. More students reported experiencing positive, need-supporting teacher practices than need-inhibiting practices. These behaviours fostered positive student-staff relationships, which were critical to students' reengagement into education. It is encouraging that students with an, often long, history of negative relationships with teachers, to the extent that they may have contributed to their disengagement, were able to build relationships of trust and respect with the AP school staff. In support of this, students generally believed that they were engaged in their studies, which was corroborated by the staff interviews and lesson observations. Importantly, it appeared that students' attendance greatly improved at the AP school, which is a key success indicator for educational re-engagement (Cook 2005). Given that these students were disengaged on their arrival at the AP school, many having been excluded from one or more mainstream schools and presenting with diverse histories and complex support needs, this finding attests to the strategy of the school, particularly, it is argued, to the teaching practices that supported fulfilment of the psychological needs. AP students are a heterogeneous group and it appears that an approach attending to their basic psychological needs is successful as it acknowledges their uniqueness.

Being treated with respect, given choices, flexibility and a non-confrontational approach all supported the need for autonomy. In each case, students described how the 
teaching practices contrasted with their previous experiences of school, and it was evident that these factors were crucial to students' re-engagement. They demonstrate instances of an understanding of staff to the background, tendencies and problems of AP students, and represent ways in which lessons were tailored to meet their demands. Respect and 'being treated like an adult' is a facilitator of re-engagement commonly found in the literature (e.g., Attwood, Croll, and Hamilton 2003; Hallam et al. 2007). The resulting mutual respect between students and school staff was important; when young people respect adults, they are more likely to listen and respond to them, as they believe they are 'on their side' and want the best for them (Frankham et al. 2007). Teaching relevant and meaningful material was an effective strategy for re-engaging the students, perhaps because it allowed them to connect their emerging identities with the academic content of their lessons (Roeser et al. 1998). Staff had also been successful in helping students to internalise the value of learning and education, which was part of the process of a student being able to regulate their own learning. Attempts to control, threats and punishments, and communication problems were all conducive to autonomy coercion. They resulted in student dissatisfaction and contrasted with the respectful and non-confrontational approach described earlier.

Regarding relatedness involvement, staff knew students personally and understood how their backgrounds impacted on their behaviour in school. These factors were important to students and have been reported elsewhere (Frelin and Grannäss 2015; Knesting and Waldron 2006). Students believed that staff cared and supported them, which may negate the greater vulnerability of AP students to poor academic outcomes and involvement in negative behaviours by assuring them that their investment in their relationship with staff will be supported and will likely pay off (Muller 2001). Staff promoted positive peer relationships which, amongst other advantages, fostered a sense of belonging. The development of a classroom 'community' in which students experience meaningful personal connections with 
others is important for students who express low satisfaction with school (Baker 1999). A minority of students reported relatedness rejection issues, in which they believed that staff had demonstrated irritation toward them or treated them unfairly. Self-reported relational adversity has been found to have a stronger relationship with behavioural engagement and achievement than relational support (Hughes, Wu, Kwok, Villarreal, and Johnson 2012). Since students reported negative student-staff relationships at their previous school(s), this may have contributed to their disengagement in the first place. It is crucial that the practices categorised as relatedness rejection are avoided in AP settings, when the goal is to re-engage students with already disrupted educational pathways.

Clarity in teaching and expectations, classwork support, and displaying confidence in students were facilitators of the need for competency, and allowed staff to provide the structure necessary to underpin learning in AP students, who were unable to self-regulate their learning, and allow them to progress (Putwain et al. 2015). Students reported that staff believed in their academic capability and this in turn, helped students to believe in themselves. Staff frequently praised students and gave positive feedback, which promotes a positive change in self-image (Frankham et al. 2007). Staff also provided an optimal level of challenge for many students, which is important as it helps disaffected students to feel respected as learners and facilitates attitude change (Schussler 2009). Conversely, other students were not satisfied with the level of challenge in lessons, which inhibited the need for competence, together with instances in which competition between peers were promoted. The latter case conveys a sense to students that their progress is judged against one another, not against their personal targets, which can be damaging for students who lack self-confidence in their ability, such as students new to the AP school, and therefore should be avoided.

Staff practices that influenced each of the three needs contributed to the quality of the student-staff relationship. Although previous research has found this relationship to predict 
student engagement, in many cases, it has actually been based on a measure of relatedness towards, or involvement with, teachers (e.g., Furrer and Skinner 2003; Roorda et al. 2011), which essentially assesses satisfaction of one of the three needs. It may be the case that the student-staff relationship is the higher-order factor of which satisfaction of all three needs contributes, however, the need for relatedness may be the most important. In support of this, Skinner and Belmont (1993) found teacher involvement to be central to children's classroom experiences; children who experienced their teachers as highly involved, also believed they provided more autonomy support and structure. It is likely that satisfaction of the need for relatedness was the critical factor in the present study. The AP school staff made a conscious effort to build personal and trusting relationships with students. This whole school approach has been reported previously (Frelin and Grannäs 2015) and is intended to provide students with the tools necessary for success.

\section{Limitations}

Generalisation of the findings to the AP student population is not possible as the study was based on one AP (free) school in one area of the UK and the sample size was small. Replication in a number of AP schools/academies is required in order to strengthen and extend the findings. The sample may have been biased, as a minority of students declined to take part in the interviews. This may have been due to personal problems, for example, some had anxiety and/or issues with self-confidence. It is possible that their feelings and experiences may have differed from those who were interviewed. As the main source of data were student interviews (self-report), there may also have been issues with trustworthiness, i.e., social desirability, problems with retrospective recall or purposeful inaccurate reporting due to the complex problems that students had. The triangulation of data with the staff interviews and lesson observations reduced the likelihood of these issues causing spurious conclusions. Future work may consider the use of experience sampling, as this allows data to 
be collected in real time which improves recall and reliability (Sinatra et al. 2015). Both students and staff reported that attendance levels, behavioural conduct and academic attainment had all improved for the vast majority of students since they began attending the AP school. Although similar conclusions have been offered, based on self-report, in the literature (e.g., Hallam et al. 2007), it would have been useful to corroborate these claims using objective data, such as attendance records, student discipline referrals and test scores. This would be a beneficial addition to future research in the area, and would also verify the final link in the self-system model (i.e., between engagement and achievement).

The present study set out to investigate the context of the school and the classroom in particular, however, it is acknowledged that other factors in the home and peer group contribute to need satisfaction and student engagement (Roeser et al. 1998). It is important to examine these different contexts using the self-system model as a framework, to allow an integrated and full description of the contextual and psychological factors underlying student engagement. Previous quantitative research has revealed demographic differences in perceptions of need satisfaction (e.g., gender, see Baard, Deci, and Ryan 2004). A further avenue for future research could be to explore these differences in the phenomenology of psychological needs using qualitative methods. Finally, although conclusions are heavily supported by the qualitative data, caution is warranted when interpreting the findings as student engagement was not measured quantitatively and psychological needs were not experimentally manipulated. It would be useful to test the strength of relationships between contextual factors, psychological needs and student engagement in an AP student population, as specified in Figure 1, using a quantitative methodology. This could include an investigation of reciprocal relationships, which have been reported previously (Reeve 2012; Skinner and Belmont 1993).

\section{Implications}


Positive student-staff interactions that supported the psychological needs were critical to the re-engagement of students attending the AP school. This supports the first three stages of the self-system model of motivational practices and extends it to an initially disengaged student population. Previous research has found that students in mainstream school with low engagement were more neglected and coerced by teachers and treated with less consistency, which exacerbates their withdrawal from education and results in a destructive cycle (Skinner and Belmont 1993). School psychologists have a valuable role to play in providing staff training on the issues that facilitate or impede re-engagement in those 'hard to reach' students, as they may not be covered during programs of initial teacher education. As a consequence, staff in both mainstream and AP schools may not be aware of the importance of creating trusting, caring relationships with students, or of allowing students to feel a sense of autonomy and competence. Furthermore, there may be a more direct role for school psychologists who may encounter such students when providing assessments for special educational or learning needs. A consideration of the best way for teachers, and other school staff, to support students, based on the self-system model, could form part of subsequent support plans for students. Fortunately, teachers' motivating style is malleable, especially the ability to adopt a more autonomy-supportive style (Reeve 2012), which is the need that demands the most intervention or training (Skinner and Belmont 1993). Educational inspection and regulation services, such as Ofsted in the UK, could also benefit from using the current findings to inform and guide their policies and inspections of both mainstream and AP schools.

From the perspective of the students (corroborated by the staff and lesson observations), the AP school was meeting the requirements set out in government policy (DfE 2013a), and was successfully re-engaging initially disengaged students back into education. To some extent, the national AP guidelines recognise the importance of a holistic 
approach (e.g., to meet the personal, social and academic needs of students), however, more specific guidance is needed. If the findings were replicated in other AP schools/academies in the UK, policy-makers could review them and consider focusing the statutory guidelines on practices that will help to meet the students' psychological needs for autonomy, relatedness and competence. If AP establishments were required by the Government to meet these needs, the importance of the role of school psychologists in training school staff and employing methods to achieve them, would be made more salient to those on the frontline. Finally, in support of current government policy, an increase in the number of AP schools, which have the scope to focus on the supportive staff practices identified here, should positively impact on the amount of students successfully completing their education. 


\section{References}

Appleton, J. J., S. L. Christenson, and M. J. Furlong. 2008. "Student engagement with school: Critical conceptual and methodological issues of the construct." Psychology in the Schools 45: 369-386. doi:10.1002/pits.20303

Appleton, J. J., S. L. Christenson, D. Kim, and A. L. Reschly. 2006. "Measuring cognitive and psychological engagement: Validation of the student engagement instrument.” Journal of School Psychology 44: 427-445. doi:10.1016/j.jsp.2006.04.002

Attwood, G., P. Croll, and J. Hamilton. 2003. "Re-engaging with education.” Research Papers in Education 18 (1): 75-95. doi:10.1080/0267152032000048596

Baard, P. P., E. L. Deci, and R. M. Ryan. 2004. Intrinsic need satisfaction: A motivational basis of performance and well-being in two work settings. Journal of Applied Social Psychology 34: 2045-2068.

Baker, J. A. 1999. “Teacher-student interaction in urban at-risk classrooms: Differential behavior, relationship quality, and student satisfaction with school." The Elementary School Journal 100: 57-70. doi:10.1086/461943

Bourdieu, P., and J. C. Passeron. 1977. Reproduction in Education, Society and Culture. Beverly Hills: Sage.

Brinkmann, S., and S. Kvale. 2014. InterViews: Learning the Craft of Qualitative Research Interviewing. London: Sage.

Connell, J. P., and J. G. Wellborn. 1991. "Competence, autonomy, and relatedness: A motivational analysis of self-system processes." Minnesota Symposia on Child Psychology 23: 43-77.

Cook, L. 2005. "School without walls: Reconnecting the disconnected at 14." Support for Learning 20: 90-95. doi:10.1111/j.0268-2141.2005.00367.x 
Cotton, D. R. E., A. Stokes, and P. A. Cotton. 2010. "Using observational methods to research the student experience.” Journal of Geography in Higher Education 34: 463473. doi:10.1080/03098265.2010.501541

D'Angelo, F., and R. Zemanick. 2009. "The twilight academy: An alternative education program that works." Preventing School Failure 53: 211-218. doi:10.3200/PSFL.53.4.211-218

Deci, E. L., R. J. Vallerand, L. G. Pelletier, and R. M. Ryan. 1991. "Motivation and education - the self-determination perspective." Educational Psychologist 26: 325-346. doi:10.1207/s15326985ep2603and4_6

Decker, D. M., D. P. Dona, and S. L. Christenson. 2007. "Behaviorally at-risk African American students: The importance of student-teacher relationships for student outcomes.” Journal of School Psychology 45: 83-109. doi:10.1016/j.jsp.2006.09.004

DfE (Department for Education). 2013a. Alternative provision: Statutory guidance for local authorities. London: HMSO.

DfE (Department for Education). 2013b. Ensuring a good education for children who cannot attend school because of health needs: Statutory guidance for local authorities. London: HMSO.

DfE (Department for Education). 2015a. 2010 to 2015 government policy: Academies and free schools. London: HMSO.

DfE (Department for Education). 2015b. 2010 to 2015 government policy: Children outside mainstream education. London: HMSO.

Dotterer, A. M., and K. Lowe. 2011. "Classroom context, school engagement, and academic achievement in early adolescence.” Journal of Youth and Adolescence 40: 1649-1660. doi:10.1007/s10964-011-9647-5 
Dupont, S., B. Galand, F. Nils, and V. Hospel. 2014. "Social context, self-perceptions and student engagement: A SEM investigation of the self-system model of motivational development (SSMMD).” Electronic Journal of Research in Educational Psychology 12: 5-32. doi:10.14204/ejrep.32.13081

Frankham, J., D. Edwards-Kerr, N. Humphrey, and L. Roberts. 2007. School exclusions: Learning partnerships outside mainstream education. Retrieved from https://www.jrf.org.uk/report/school-exclusions-learning-partnerships-outsidemainstream-education

Fredricks, J. A., P. C. Blumenfeld, and A. H. Paris. 2004. "School engagement: Potential of the concept, state of the evidence." Review of Educational Research 74: 59-109. doi:10.3102/00346543074001059

Frelin, A., and J. Grannäs. 2015. "Direct and indirect educational relationships: Developing a typology for the contribution of different categories of school staff in relation to students' educational experiences.” Improving Schools 18: 56-68. doi:10.1177/1365480214562124

Furrer, C., and E. Skinner. 2003. "Sense of relatedness as a factor in children's academic engagement and performance." Journal of Educational Psychology 95: 148-162. doi:10.1037/0022-0663.95.1.148

Furrer, C. J., E. A. Skinner, and J. R. Pitzer. 2014. "The influence of teacher and peer relationships on students' classroom engagement and everyday motivational resilience." National Society for the Study of Education 113: 101-123.

Greene, B. A. 2015. "Measuring cognitive engagement with self-report scales: Reflections from over 20 years of research.” Educational Psychologist 50: 14-30. doi:10.1080/00461520.2014.989230 
Hallam, S., L. Rogers, J. Rhamie, J. Shaw, E. Rees, H. Haskins, J. Blackmore, and J. Hallam. 2007. "Pupils' perceptions of an alternative curriculum: Skill force." Research Papers in Education 22 (1): 43-63. doi:10.1080/02671520601152078

Hodkinson, P., and A. C. Sparkes. 1997. Careership: A sociological theory of career decision making. British Journal of Sociology of Education 18: 29-44. doi:10.1080/0142569970180102

Hughes, J. N., J. Y. Wu, O. M. Kwok, V. Villarreal, and A. Y. Johnson. 2012. "Indirect effects of child reports of teacher-student relationship on achievement." Journal of Educational Psychology 104: 350-365. doi:10.1037/a0026339

Jones, J. 2011. "Narratives of student engagement in an alternative learning context." Journal of Education for Students Placed at Risk 16 219-236. doi:10.1080/10824669.2011.586299

Knesting, K., and N. Waldron. 2006. "Willing to play the game: How at-risk students persist in school." Psychology in the Schools 43: 599-611. doi:10.1002/pits.20174

Lent, R. W., S. D. Brown, and G. Hackett. 1994. Toward a unifying social cognitive theory of career and academic interest, choice, and performance. Journal of Vocational Behavior 45: 79-122. doi:10.1006/jvbe.1994.1027

Lincoln, Y. S., and E. G. Guba. 1985. Naturalistic Inquiry. Newbury Park, CA: Sage.

Madill, A., and B. Gough. 2008. Qualitative research and its place in psychological science. Psychological Methods 13: 254-271. doi:10.1037/a0013220

Martin, A. J. 2007. "Examining a multidimensional model of student motivation and engagement using a construct validation approach.” British Journal of Educational Psychology 77: 413-440. doi:10.1348/000709906X118036

Muller, C. 2001. "The role of caring in the teacher-student relationship for at-risk students.” Sociological Inquiry 71: 241-255. doi:10.1111/j.1475-682X.2001.tb01110.x 
Ofsted (Office for Standards in Education, Children's Services and Skills). 2016. Alternative provision: The findings from Ofsted's three-year survey of school's use of off-site alternative provision. Manchester: HMSO.

Park, S., S. D. Holloway, A. Arendtsz, J. Bempechat, and J. Li. 2012. "What makes students engaged in learning? A time-use study of within- and between-individual predictors of emotional engagement in low-performing high schools." Journal of Youth and Adolescence 41: 390-401. doi:10.1007/s10964-011-9738-3

Pianta, R., B. Hamre, and J. Allen. 2012. “Teacher-student relationships and engagement: Conceptualizing, measuring, and improving the capacity of classroom interactions." In Handbook of Research on Student Engagement, edited by S. L. Christenson, A. L. Reschly and C. Wylie, 365-386. Boston, MA: Springer US. doi:10.1007/978-1-46142018-7_17

Pietkiewicz, I., and J. A. Smith. 2014. “A practical guide to using interpretative phenomenological analysis in qualitative research psychology." Czasopismo Psychologiczne - Psychological Journal 20: 7-14. doi:10.14691/CPPJ.20.1.7

Pirrie, A., G. Macleod, M. A. Cullen, and G. McCluskey. 2011. "What happens to pupils permanently excluded from special schools and pupil referral units in England?" British Educational Research Journal 37: 519-538. doi:10.1080/01411926.2010.481724

Putwain, D. W., L. J. Nicholson, and J. L. Edwards. 2015. "Hard to reach and hard to teach: Supporting the self-regulation of learning in an alternative provision secondary school.” Educational Studies 42 (1): 1-18. doi:10.1080/03055698.2015.1108839

Reeve, J. 2012. “A self-determination theory perspective on student engagement.” In Handbook of Research on Student Engagement, edited by S. L. Christenson, A. L. Reschly and C. Wylie, 365-386. Boston, MA: Springer US. doi:10.1007/978-1-46142018-7_7 
Reschly, A., and S. Christenson. 2012. "Jingle, jangle, and conceptual haziness: Evolution and future directions of the engagement construct." In Handbook of Research on Student Engagement, edited by S. L. Christenson, A. L. Reschly and C. Wylie, 365-386. Boston, MA: Springer US. doi:10.1007/978-1-4614-2018-7_1

Roehrig, A. D., and E. Christesen. 2010. "Development and use of a tool for evaluating teacher effectiveness in grades K-12." In Innovative Assessment for the 21st Century, edited by V. J. Shute and B. J. Becker, 207-228. New York: Springer. doi:10.1007/978-1-4419-6530-1_12

Roeser, R. W., J. S. Eccles, and A. J. Sameroff. 1998. "Academic and emotional functioning in early adolescence: Longitudinal relations, patterns, and prediction by experience in middle school." Development and Psychopathology 10: 321-352. doi:10.1017/S0954579498001631

Roorda, D. L., H. M. Y. Koomen, J. L. Spilt, and F. J. Oort. 2011. "The influence of affective teacher-student relationships on students' school engagement and achievement: A metaanalytic approach.” Review of Educational Research 81: 493-529. doi:10.3102/0034654311421793

Ryan, R. M., and E. L. Deci. 2000. "Self-determination theory and the facilitation of intrinsic motivation, social development, and well-being.” American Psychologist 55: 68-78. doi:10.1037/0003-066X.55.1.68

Ryan, R. M., and E. L. Deci. 2009. "Promoting self-determined school engagement: Motivation, learning, and well-being." In Handbook on Motivation at School, edited by K. R. Wentzel and A. Wigfield, 171-195. New York: Routledge.

Schussler, D. 2009. "Beyond content: How teachers manage classrooms to facilitate intellectual engagement for disengaged students." Theory into Practice 48: 114-121. doi:10.1080/00405840902776376 
Sinatra, G. M., B. C. Heddy, and D. Lombardi. 2015. "The challenges of defining and measuring student engagement in science.” Educational Psychologist 50: 1-13. doi:10.1080/00461520.2014.1002924

Skinner, E. A., and M. J. Belmont. 1993. "Motivation in the classroom: Reciprocal effects of teacher behavior and student engagement across the school year." Journal of Educational Psychology 85: 571-581. doi:10.1037/0022-0663.85.4.571

Skinner, E. A., T. A. Kindermann, and C. J. Furrer. 2009. "A motivational perspective on engagement and disaffection: Conceptualization and assessment of children's behavioral and emotional participation in academic activities in the classroom." Educational and Psychological Measurement 69: 493-525.

Smith, J. A., and M. Osborn. 2003. "Interpretative phenomenological analysis.” In Qualitative Psychology: A Practical Guide to Methods edited by J. A. Smith, 51-80. London: Sage.

Smith, J. A., P. Flowers, and M. Larkin. 2009. Interpretative Phenomenological Analysis: Theory, Method and Research. London: Sage.

Tobin, T., and J. Sprague. 2000. "Alternative education strategies: Reducing violence in school and the community." Journal of Emotional and Behavioral Disorders 8: 177-186. doi:10.1177/106342660000800305

Van Ryzin, M. J., A. A. Gravely, and C. J. Roseth. 2009. “Autonomy, belongingness, and engagement in school as contributors to adolescent psychological well-being." Journal of Youth and Adolescence 38: 1-12. doi:10.1007/s10964-007-9257-4

White, R., K. Martin, and J. Jeffes. 2010. The back on track alternative provision pilots: Final report. Retrieved from https://www.gov.uk/government/uploads/system/uploads/attachment_data/file/183516/D $\underline{\text { FE-RR250.pdf }}$ 
Zimmer-Gembeck, M. J., H. M. Chipuer, M. Hanisch, P. A. Creed, and L. McGregor. 2006.

"Relationships at school and stage-environment fit as resources for adolescent engagement and achievement." Journal of Adolescence 29: 911-933.

doi:10.1016/j.adolescence.2006.04.00 
Figure 1. The self-system model of motivational processes (adapted from Connell and Wellborn 1991, with elements from Furrer et al. 2014)

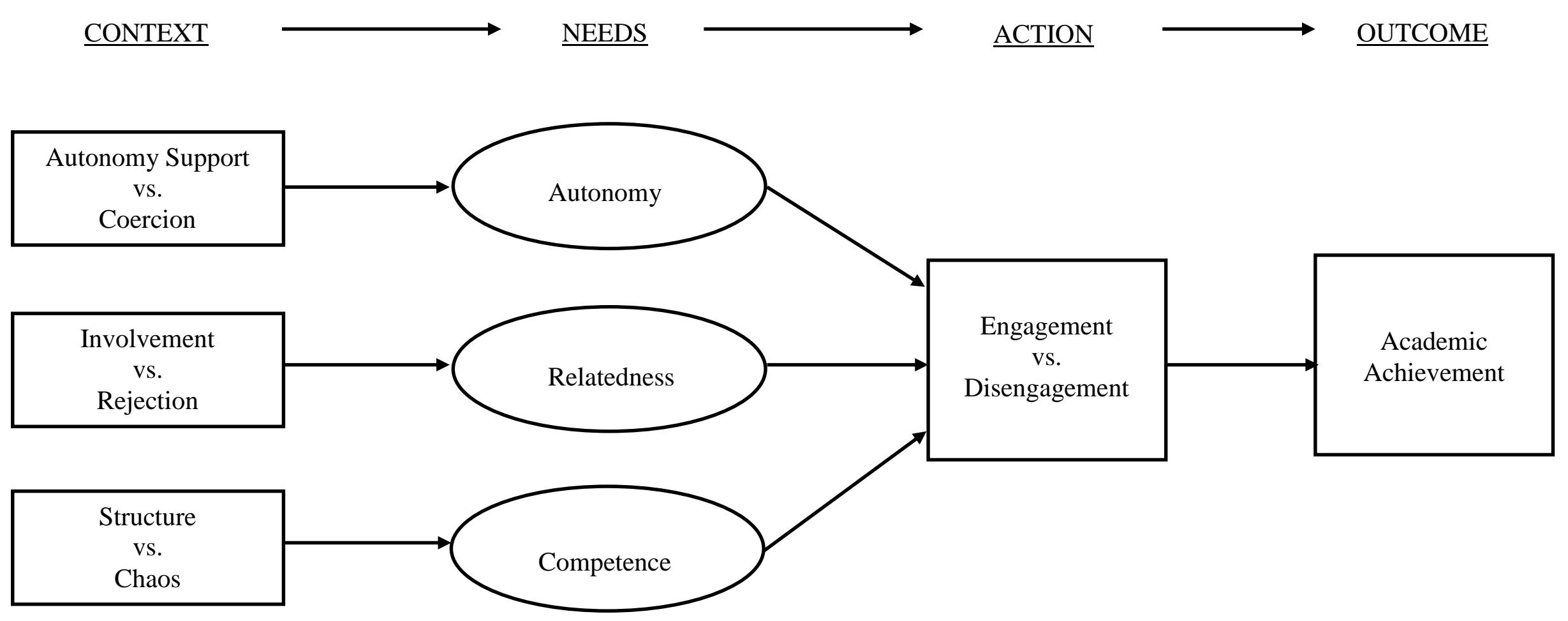

